\title{
Improving maternal and child healthcare programme using community-participatory interventions in Ebonyi State Nigeria
}

\author{
Chigozie Jesse Uneke ${ }^{1, *}$, Chinwendu Daniel Ndukwe ${ }^{2}$, Abel Abeh Ezeoha ${ }^{3}$, Henry Chukwuemeka \\ Urochukwu $^{4}$, Chinonyelum Thecla Ezeonu ${ }^{5}$
}

Abstract

In Nigeria, the government is implementing the Free Maternal and Child Health Care Programme (FMCHCP). The policy is premised on the notion that financial barriers are one of the most important constraints to equitable access and use of skilled maternal and child healthcare. In Ebonyi State, Southeastern Nigeria the FMCHCP is experiencing implementation challenges including: inadequate human resource for health, inadequate funding, out of stock syndrome, inadequate infrastructure, and poor staff remuneration. Furthermore, there is less emphasis on community involvement in the programme implementation. In this policy brief, we recommend policy options that emphasize the implementation of community-based participatory interventions to strengthen the government's FMCHCP as follows: Option 1: Training community women on prenatal care, life-saving skills in case of emergency, reproductive health, care of the newborn and family planning. Option 2: Sensitizing the community women towards behavioural change, to understand what quality services that respond to their needs are but also to seek and demand for such. Option 3: Implementation packages that provide technical skills to women of childbearing age as well as mothers' groups, and traditional birth attendants for better home-based maternal and child healthcare. The effectiveness of this approach has been demonstrated in a number of community-based participatory interventions, building on the idea that if community members take part in decision-making and bring local knowledge, experiences and problems to the fore, they are more likely to own and sustain solutions to improve their communities' health.

Keywords: Maternal, Child, Healthcare, Community-Participation, Nigeria

Copyright: @ 2014 by Kerman University of Medical Sciences

Citation: Uneke CJ, Ndukwe CD, Ezeoha AA, Urochukwu HC, Ezeonu CT. Improving maternal and child healthcare programme using community-participatory interventions in Ebonyi State Nigeria. Int J Health Policy Manag 2014; 3: 283-287. doi: 10.15171/ijhpm.2014.91

\section{Article History:}

Received: 21 June 2014 Accepted: 24 September 2014 ePublished: 25 September 2014
Statement of the issue/problem and a background of the problem

At an estimated 350 US dollars per capita annually, Nigeria still ranks near the bottom 158 out of 177 countries in the United Nations Human Development Index (HDI) in terms of per capita income, with more than half of the population living in poverty (1). Nigeria with a population of over 150 million has one of the weakest health systems in the world and was ranked $187^{\text {th }}$ out of 191 member states by the World Health Organization (WHO) in 2000. Due to the weak health systems, maternal and child health status in Nigeria is among the worst in Africa. With approximately $2.5 \%$ of the world's population, Nigeria has more than $10 \%$ of all under- 5 and maternal deaths - more than 1 million newborn, infant, and child deaths and more than 50,000 maternal deaths every year $(1,2)$.

Annually, an estimated 52,900 Nigerian women die from pregnancy related complications, out of 529,000 global maternal deaths, thus a woman's chance of dying from pregnancy and childbirth in Nigeria is 1 in 13 (3). The main causes of maternal mortality in Nigeria are: haemorrhage $(23 \%)$, infection (17\%), unsafe abortion (11\%), obstructed labour (11\%) and toxaemia/eclampsia/hypertension (11\%),
Malaria (11\%), anaemia (11\%) and others including HIV and AIDS contribute about (5\%) (1-4). Other factors underlying maternal mortality include lack of awareness about complications in pregnancy and on the need to seek medical intervention early; lack of transportation to the health facilities where maternal healthcare can be provided; inability to pay for services, etc. $(1,3-5)$.

However, there has been a reduction in National Maternal Mortality Rate (MMR) from $800 / 100,000$ in 2005 (4) to $545 / 100,000$ according to the recent Nigeria Demographic and Health Survey (NDHS) 2008 (6). This reduction in MMR may be attributed to the various maternal and child health intervention programmes introduced by the government. One of such intervention programmes is the Free Maternal and Child Health Care Programme (FMCHCP). Ebonyi State in Southeastern Nigeria is one of the states implementing the FMCHCP in secondary and tertiary public and private health facilities. The policy is pursued against the backdrop of existing inequities in maternity and paediatric care services accessibility and utilization, and is premised on the notion that financial barriers are one of the most important constraints to equitable access and use of skilled maternal and child healthcare (7). The services provided in the FMCHCP

Full list of authors' affiliations is available at the end of the article. 
of Ebonyi State include free Antenatal Care (ANC) (including card and antenatal drugs), free vaginal and assisted vaginal delivery (forceps and vacuum), free caesarean section (elective and emergency), free post abortion care services, free management of ectopic and free laparotomy for obstetric complications, free vesicovaginal fistula repairs (8-10).

Findings from studies conducted in the two Nigerian States of Kano and Enugu indicate that the FMCHCP contributed to increased access to health services and improved maternal and child health $(9,10)$. In most Nigeria States including Ebonyi, despite the implementation of FMCHCP, utilization of maternal healthcare services is still poor especially in the rural areas, with over $65 \%$ of the women delivering at home $(3,4,9,10)$. It is based on this premise that the option of the implementation of community-based participatory interventions is proposed as innovative strategies to improve and sustain the government's FMCHCP. Community participation in health interventions in Ebonyi State has been limited in scope, organization and impact. This policy brief is designed to promote the use of community participatory approach to enhance and strengthen the FMCHCP in Ebonyi State.

Description of the current situation of the Free Maternal and Child Health Care Programme (FMCHCP)

Ebonyi State has 13 Local Government Areas (LGAs) and the population was $2,176,947$ by the 2006 national census, with a growth rate of $3.5 \%$ per annum. The State has weak health system. The life expectancy at birth in Ebonyi State was 46 years for females and 45 years for males in 2006. The Infant Mortality Rate (IMR) has remained high and is estimated at 99 per 1000 live births while the Under age 5 Mortality Rate (U5MR) is 191 per 1000 live births. Ebonyi State has Maternal Mortality Rate (MMR) of 602 per 100,000 population, which is one of the highest MMR in Nigeria (11). Available reports indicate that the underlying factors that account for the high MMR in Ebonyi State include: poverty (especially in the rural areas), ignorance, cultural belief, inadequate health facilities, unskilled birth attendants etc. (8).

As a result of the commitment of Ebonyi State government to addressing the high maternal mortality, the FMCHCP was introduced in the State in 2003. The programme was however limited to the Ebonyi State University Teaching Hospital located in Abakaliki, the State capital. Although the package was comprehensive and consisted of complete obstetric care including Emergency Obstetric Care (EOC) to the beneficiaries, unfortunately the target group, poor rural dwellers, were missed due to lack of awareness, bad road networks, poverty, first and second level delays, etc. (8). The present administration in a bid to revamp the FMCHCP and make it more functional and accessible, extended the services to all the major secondary health facilities located in the 13 local government areas in the State.

However, like the FMCHCP being executed in other parts of Nigeria, the FMCHCP in Ebonyi State is experiencing major challenges and constraints in the implementation at the various designated secondary health facilities. The key challenges and constraints include the following (8-10): (i). Inadequate manpower: The FMCHCP abolished user fees and tremendously increased the number of women accessing the services without a commensurate increase in the number of health professionals attending to them. This resulted in inadequate manpower to cope with the increase in the number of patients and therefore adversely affected the quality of maternal service delivery.

(ii). Poor remuneration of staff: The FMCHCP increased workload for the health professionals working at the maternal and child care units. Unfortunately, there was no corresponding increase in the remuneration of the health workers. Consequently, the morale of the health workers became low and their attitudes to work very poor.

(iii). Inadequate infrastructure and facilities: The increase in the patient flow placed so much pressure on the few available facilities and infrastructure at the secondary health facilities in the LGAs.

(iv). Out of stock syndrome: Due to the weak health systems, out of stock syndrome was a frequent occurrence. This affected the delivery of maternal health services rendered at the health facilities.

(v). Lack of participation of the LGA authorities in the FMCHCP: Because the programme is being implemented in the secondary health facilities funded by the State Government, the LGA authorities appear not to play any contributory role to the programme. This has limited the impact of the programme in terms of improving the access and scope of the programme to primary healthcare facilities.

Policy options and implementation strategies for addressing the problem

Policy option 1

Training of women using participatory adult learning methods, as Voluntary Maternal/Neonatal Caregivers (VMNC) and Safe Motherhood Promoters (SMP). Also training for community-based healthcare providers [Traditional Birth Attendants (TBAs), midwives, and Community Health Workers (CHWs)].

\section{Implementation strategy}

A multidisciplinary epidemiological team can be set up consisting of medical experts, researchers and policy-makers from the health ministry. Special training sessions can be organized periodically for women community organizations. The training will focus on the following: recognition of danger signs during pregnancy; labour/delivery; the postpartum period and in the newborn; prenatal care to prevent complications from occurring or becoming serious; life-saving skills in case of emergency when no other recourse exists; haemorrhage and anaemia; retention of the placenta; reproductive health and sex education; care of the newborn; family planning. This approach has been shown to work in numerous community based interventions to improve maternal health in resource constrained communities

\section{Policy Option 2}

Community mobilization and the empowerment of 
individuals and communities to demand quality services that respond to their needs. Family-oriented and communityoriented services support self care (antenatal/intrapartum/ postnatal family-community care), including the adoption of improved care practices and appropriate care seeking for illness. This option is principally targeted at sensitizing the community women towards behavioural change, not only to understand what quality services that respond to their needs are but also to seek and demand for such quality services as their fundamental right.

\section{Implementation strategy}

Women of childbearing age in the community can be sensitized through the health department of the various LGAs. These services can be provided by various health workers, and should be tailored to the community's social and cultural environment. Examples of family-community care include: behaviour change communications; community mobilisation and engagement to stimulate adoption of improved antenatal, intrapartum, and postnatal care practices; care seeking for illness; and, community-based case management of illness-e.g. pneumonia-by community health workers (21). Evidence-based neonatal care practices (breastfeeding, thermal care, clean cord care), and promotion and practice of clean delivery and referral of complications (for home births); Extra home visits and support for breastfeeding and quarterly community outreaches to create demand for services $(20,21)$.

\section{Policy Option 3:}

Implementation of community-based participatory interventions to strengthen and broaden the scope of the FMCHCP. This option focuses principally on the provision of technical skills to the women of childbearing age as well as mothers' groups, and traditional birth attendants for better home-based maternal and child healthcare. This is to be achieved by introducing the following packages which were proven as very effective in previous studies $(20,21)$ :

i) Community-based birth preparedness package: It is a social mobilization programme to promote the behaviour of families to prepare for birth by engaging volunteers to counsel the mothers and families during home visits as well as during the community group meetings $(12,16,17,21-23)$.

ii) Community-based newborn care package: The package consists of service delivery component, home visitation as well as community mobilisation to enhance skills on community case management of infection, home-based care of Low Birth Weight (LBW), and birth asphyxia as well as orientation to mothers' group, traditional healer and traditional birth attendant about the programme $(12,13,15-17,21,24)$.

iii) Community-based infant and young child feeding package: is a package having counselling component on early breast feeding, exclusive breast feeding, extended breast feeding, complementary feeding and food diversification $(16,20,25)$.

iv) Community-based integrated management of childhood illness package: This is a package which has a service delivery component such as the delivery of commodities as well as community participation and the promotion of positive health behaviours and enhancement of skills for home-based management of pneumonia and diarrhoea as well as orientation to mothers about the programme in the community $(16,20,22,23)$.

\section{Implementation strategy}

The implementation package will consists principally of providing technical skills to women of childbearing age as well as mothers' groups, and traditional birth attendants for better home-based maternal and child healthcare. The Community Action Cycle (CAC) frame described in previous studies $(20,21)$ can be employed to understand the community context, exploration of the issue to understand what is being currently done and why (helpful, harmful and benign practices, belief and attitudes), setting the priorities, planning together with the communities, monitoring and evaluating the progress. The three-stage $\mathrm{CAC}$ frame described in previous studies $(20,21)$ are is outlined below:

Stage 1: Identifying and prioritizing problems together

The women's groups will identify and prioritize maternal and neonatal health problems at the community level via the following steps:

i. Orientation of the women to the FMCHCP improvement intervention project

ii. Identifying challenges associated with access to the FMCHCP

iii. Implementing woman-to-woman interviews in the home to obtain more information on maternal/child health and the FMCHCP

iv. Prioritizing the problems of maternal/child health and the FMCHCP.

Stage 2: Planning strategies together

The purpose is to define strategies and actions to resolve the problems identified by the women's groups through a process of planning together via the following steps:

i. Presentation of problems by the women: The women's groups will learn about the problems of maternal/child health and will know why they are priority problems.

ii. Identifying barriers to solving the problems: The women's groups will understand what a barrier is and will identify barriers to solving the problems of maternal/child health and the FMCHCP portrayed by the women.

iii. Identifying strategies and realistic, concrete actions: The women's groups will identify strategies and realistic, concrete actions which will help to lessen or overcome the barriers of maternal/child health.

Stage 3: Training of the women

Organizing training sessions on the intervention packages: i) Community-based birth preparedness package; ii) Community-based newborn care package; iii) Communitybased infant and young child feeding package; iv) Community-based integrated management of childhood illness package.

\section{Justification of recommended policy options}

In this policy brief, different policy options are suggested to establish community-based participatory approach to strengthen the government's FMCHCP. Scientific evidence abound which indicates that this approach can improve 
health interventions in low income settings by promoting the following (19):

i) Empowerment of people and communities: A number of previous reports have argued that well-designed communitybased projects have the potential to be more inclusive, to empower communities, including poor and marginalized groups, and strengthen linkages between civil society and government $(19,26,27)$.

ii) Improve efficiency, effectiveness, and sustainability of interventions: Evidence from community-based studies indicates that community-based interventions have the potential to be more responsive to the needs and priorities of beneficiaries (allocative efficiency) (19). The findings from the studies reported by McLeod (28) and Rawlings et al. (29) showed that community-based projects are comparatively cost effective (productive efficiency) because of lower levels of bureaucracy and better knowledge of local costs.

iii) Build organizational capacity at local level: Slaymaker and colleagues (19) in their report noted that in theory, mobilization of communities to identify problems and plan and manage projects helps strengthen local capacity for collective action. Furthermore, McLeod and Tovo (30) demonstrated in their studies that additional benefits of community-based participatory projects are often observed beyond the scope of the original project, e.g. formation of selfhelp groups and micro enterprise development.

iv) Strengthen local governance: Community-driven development is increasingly being promoted as a means of strengthening state-community synergies (31). Emerging demand-driven approaches theoretically 'empower' communities to command services and provide a mechanism for (re)building trust and accountability and reestablishing the 'social contract' between communities and government (19).

In conclusion we recommend the community-based participatory interventions to strengthen the FMCHCP, based on findings of the evaluation of impact of similar programmes showing the effectiveness of community-based participatory interventions (12-16,32). Several community mobilization interventions have used a participatory approach, building on the idea that if mothers and other community members take part in decision-making and bring local knowledge, experiences and problems to the fore, they are more likely to own and sustain solutions to improve their communities' health (32). The rationale for using communitybased interventions is based on the fact that many maternal and neonatal deaths occur at home, and could potentially be avoided by changes in antenatal and newborn care practice and better understanding of health problems.

\section{Acknowledgements}

This policy brief was a product of the project funded by the World Health Organization/International Development Research Centre (IDRC) on Promoting innovation in evidence-informed policy-making in Knowledge Translation Platforms in Sub-Saharan Africa (Ref. No. 2012/2371920; PO. 200571438). We are grateful to Dr. Ulysses Panniset of the Evidence and Networks for Health Unit, Knowledge Management and Sharing (KMS/IER) World Health Organization for hisvaluable suggestions/guidance. We thank Sandy Campbell and Dr. Fadi El-Jardali for the technical assistance and advice they provided to the Team in this project.

Ethical issues

Not applicable.

Competing interests

The authors declare that they have no competing interests.

Authors' contributions

CJU, CDN, and AEE conceived the idea. All authors contributed to the development of the idea, drafting and revision of the policy brief.

\section{Authors' affiliations}

${ }^{1}$ Department of Medical Microbiology/Parasitology, Faculty of Clinical Medicine, Ebonyi State University, Abakaliki, Nigeria; and Health Policy and Systems Research Project (Knowledge Translation Platform), Ebonyi State University, Abakaliki, Nigeria. ${ }^{2}$ National Agency for the Control of AIDS, Abuja, Nigeria. ${ }^{3}$ Department of Banking and Finance, Ebonyi State University, Abakaliki, Nigeria. ${ }^{4}$ Department of Social Mobilization and Disease Control, National Obstetrics Fistula Centre, Abakaliki, Nigeria. ${ }^{5}$ Department of Paediatrics, Ebonyi State University, Abakaliki, Nigeria.

\section{References}

1. United States Agency for International Development (USAID). Working Toward the Goal of Reducing Maternal and Child Mortality: USAID Programming and Response. Washington, DC; 2008. Available from: http://pdf.usaid.gov/pdf_docs/PDACL707. pdf

2. Galandanci H, Ejembi C, lliyasu Z, Alagh B, Umar U. Maternal health in Northern Nigeria-a far cry from ideal. BJOG 2007; 114: 448-52. doi: 10.1111/j.1471-0528.2007.01229.x

3. Federal Ministry of Health. Integrated Maternal, Newborn and Child Health Strategy. Abuja: Federal ministry of Health; 2007.

4. Ebonyi State Mother and Child Care Initiative (MCCl) Nigeria. Documentation commissioned by The United Nations Population Fund (UNFPA). Final Report, October 2010.

5. Federal Ministry of Health. The Maternal Newborn Roadmap. Abuja: Federal Ministry of Health; 2005.

6. National Population Commission (Nigeria). Nigeria Demographic and Health Survey 2008. Abuja: National Population Commission and ICF Macro; 2009.

7. Kuumuori G. Barriers to accessing and using formal antenatal, delivery and postnatal care services in Ghana in the context of a free maternal healthcare policy [internet]. Ethox Centre, University of Oxford, Uk. [cited July 2014]. Available from: http:// www.ethox.ox.ac.uk/research-1/global-health-ethics/barriers-toaccessing-and-using-formal-antenatal-delivery-and-postnatalcare-services-in-ghana-in-the-context-of-a-free-maternalhealthcare-policy

8. Ministry of Health and Environment, Abakaliki, Ebonyi State. Ebonyi State Free Maternal Healthcare Program at a Glance [internet]. [cited July 2014]. Available from: http://www. ebonyionline.com/zzz-profile-ebonyi-free-maternal-healthcareprogram.html

9. Okeibunor JC, Onyeneho NG, Okonofua FE. Policy and programs for reducing maternal mortality in Enugu State, Nigeria. Afr J Reprod Health 2010; 14: 19-30.

10. Galadanci HS, Idris SA, Sadauki HM, Yakasai IA. Programs and policies for reducing maternal mortality in Kano State, Nigeria: a review. Afr J Reprod Health 2010; 14: 31-6. 
11. Ebonyi State, Ministry of Health. State Strategic Development Plan 2010-2015. Abakaliki: Ebonyi State, Ministry of Health; 2010.

12. Tripathy P, Nair N, Mahapatra R, Rath S, Gope RK, Rath S, et al. Community mobilisation with women's groups facilitated by Accredited Social Health Activists (ASHAs) to improve maternal and newborn health in underserved areas of Jharkhand and Orissa: study protocol for a cluster-randomised controlled trial. Trials 2011; 12: 182. doi: 10.1186/1745-6215-12-182

13. Kumar V, Mohanty S, Kumar A, Misra R, Santosham M, et al. Effect of community-based behaviour change management on neonatal mortality in Shivgarh, Uttar Pradesh, India: a clusterrandomised controlled trial. Lancet 2008; 372: 1151-62. doi: 10.1016/s0140-6736(08)61483-x

14. Tripathy PK, Nair N, Barnett S, Mahapatra R, Borghi J, Rath S, et al. Effect of a participatory intervention with women's groups on birth outcomes and maternal depression in Jharkhand and Orissa, India: a cluster-randomised controlled trial. Lancet 2010; 375: 1182-92. doi: 10.1016/s0140-6736(09)62042-0

15. Manandhar D, Osrin D, Shrestha B, Mesko N, Morrison J, Tumbahangphe KM, et al. Effect of a participatory intervention with women's groups on birth outcomes in Nepal: cluster randomized controlled trial. Lancet 2004; 364: 970-79. doi: 10.1016/s0140-6736(04)17021-9

16. Lewycka S, Mwansambo C, Kazembe P, Phiri T, Mganga A, Rosato $\mathrm{M}$, et al. A cluster randomised controlled trial of the community effectiveness of two interventions in rural Malawi to improve health care and to reduce maternal, newborn and infant mortality. Trials 2010; 11: 88. doi: 10.1186/1745-6215-11-88

17. Shah More N, Bapat U, Das S, Patil S, Porel M, Vaidya L, et al. Cluster-randomised controlled trial of community mobilisation in Mumbai slums to improve care during pregnancy, delivery, postpartum and for the newborn. Trials 2008; 9: 7. doi: 10.1186/1745-6215-9-7

18. Grabman L, Seoane G, Davenport C. The Warmi Project: a participatory approach to improve maternal and neonatal health: An implementer's manual. Westport: John Snow International, Mothercare Project, Save the Children; 2002.

19. Slaymaker T, Christiansen K, Hemming I. Community-based approaches and service delivery: Issues and options in difficult environments and partnerships [internet]. Overseas Development Institute, 2005. [cited July 2014]. Available from: www.odi.org.uk/resources/docs/3822.pdf

20. Howard-Grabman L, Seoane G, Davenport C. The Warmi
Project: a participatory approach to improve maternal and neonatal health: An implementer's manual. Westport: John Snow International, Mothercare Project, Save the Children; 2002.

21. Darmstadt GL, Bhutta ZA, Cousens S, Adam T, Walker N, de Bernis L. Lancet Neonatal Survival Steering Team. Evidencebased, cost-effective interventions: how many newborn babies can we save? Lancet 2005; 365: 977-88. doi: 10.1016/s01406736(05)71088-6

22. Theodoratou E, Al-Jilaihawi S, Woodward F, Ferguson $\mathrm{J}$, Jhass A, Balliet M, et al. The effect of case management on childhood pneumonia mortality in developing countries. Int $J$ Epidemiol 2010; 39: i155-71. doi: 10.1093/ije/dyq032

23. Das JK, Lassi ZS, Salam RA, Bhutta ZA. Effect of community based interventions on childhood diarrhea and pneumonia: uptake of treatment modalities and impact on mortality. BMC Public Health 2013; 13: S29. doi: 10.1186/1471-2458-13-s3-s29

24. Dongre AR, Deshmukh PR, Garg BS. A community based approach to improve health care seeking for newborn danger signs in rural Wardha, India. Indian J Pediatr 2009; 76: 45-50. doi: 10.1007/s12098-009-0028-y

25. Morrison J, Tamang S, Mesko N, Osrin D, Shrestha $\mathrm{B}$, Manandhar M, et al. Women's health groups to improve perinatal care in rural Nepal. BMC Pregnancy Childbirth 2005; 5 : 6. doi: 10.1186/1471-2393-5-6

26. Narayan D. Designing Community Based Development. Washington, DC: World Bank; 1995

27. Dongier P, van Domelen J, Ostrom E, Ryan A, Wakeman W, Bebbington A, et al. Community Driven Development. Chapter 9 in PRSP Sourcebook. Washington, DC: The World Bank; 2003.

28. McLeod D. Community-Based Social Services: Practical Advice Based upon Lessons from Outside the World Bank. Washington, DC: Social Protection Unit, The World Bank; 2003

29. Rawlings LB, Sherburne-Benz L, van Domelen J. Evaluating Social Funds: A Cross-Country Analysis of Community Investments. Washington, DC: The World Bank; 2004.

30. McLeod D, Tovo M. Social Services Delivery through CommunityBased Projects. Washington, DC: The World Bank; 2001.

31. Das Gupta M, Grandvoinnett H, Romani M. State-Community Synergies in Community-Driven Development. J Dev Stud 2004; 40: 27-58. doi: 10.1080/0022038042000213193

32. Howard-Grabman. Demystifying community mobilisation: an effective strategy to improve maternal and newborn health [internet]. 2007. [cited July 2014]. Available from: http://pdf. usaid.gov/pdf_docs/PNADI338.pdf 